\title{
Towards best possible safety - current regulatory research for the German site selection process for high-level radioactive waste disposal
}

\author{
Axel Liebscher, Christoph Borkel, Michael Jendras, Ute Maurer-Rurack, and Carsten Rücker \\ Division Research on Site Selection and Public Participation; Research on Nuclear Waste Management/Nuclear Safety \\ (Interdisciplinary Topics), Federal Office for the Safety of Nuclear Waste Management (BASE), Berlin, 10623, Germany
}

Correspondence: Christoph Borkel (christoph.borkel@bfe.bund.de)

Received: 22 June 2020 - Revised: 15 September 2020 - Accepted: 23 September 2020 - Published: 3 December 2020

\begin{abstract}
The Federal Office for the Safety of Nuclear Waste Management (BASE - Bundesamt für die Sicherheit der nuklearen Entsorgung) is the German federal regulatory authority for radioactive waste disposal. It supervises the German site selection process and is responsible for the accompanying public participation. Task related research is an integral part of BASE's activities. The projects MessEr and übErStand compiled the state-of-the-art science and technology regarding surface based exploration methods suitable for addressing the criteria and requirements specified in the German Site Selection Act. The results support BASE to review and define the surface-based exploration programs to be executed by the national implementer BGE (Bundesgesellschaft für Endlagerung $\mathrm{mbH}$ ). To support BASE in reviewing the application of the exclusion criteria "active fault zones" according to the Site Selection Act, the project KaStör reviewed the current knowledge on active faults and fault zones in Germany and recommends methodological approaches to date and identify the activity of faulting. For the time being, the Site Selection Act defines $100^{\circ} \mathrm{C}$ as a draft limit on the temperature at the outer surface of a repository container for all host rocks. The project Grenztemperatur studied the temperature dependency of the different thermal-hydraulicmechanical-chemical/biological (THMC/B) processes according to available features-events-processes (FEP) catalogues for rock salt, clay stone, and crystalline rock and describes ways to defining host rock specific maximum temperatures based on specific disposal and safety concepts. Safety oriented weighting of different criteria and comparison of different potential regions and sites are key challenges during the siting process. The project $M A B e S t$ studied and reviewed methodological approaches to this weighting and compari-
\end{abstract}

son problem with special emphasis on multi criteria analysis (MCA) and multi criteria decision analysis (MCDA). A key requirement for safe geological disposal of nuclear waste is barrier integrity. The project PeTroS performed the first triaxial flow-through experiments on natural rock salt samples at disposal relevant $p-T$ conditions and studied potential percolation mechanisms of fluids within rock salt. The data substantiate that the minimum stress criterion and/or the dilatancy criterion are the prime "percolation thresholds" in rock salt. The research results support BASE in fulfilling its tasks as national regulator according to state-of-the-art science and technology and are also relevant to other stakeholders of the siting process.

\section{Introduction}

The German Site Selection Act (2017) defines the search and selection of the national German site with best possible safety for a disposal facility for high-level radioactive waste. This process is supposed to be transparent, based on scientific insights and free of preconceived opinions as to its outcome. The objective is to find a repository site that will offer the best possible safety for one million years. The stepwise siting process is subdivided into three phases (Fig. 1): During Phase 1, first sub-areas and then siting regions with favourable geologic conditions are determined. For the siting regions, surface exploration programs are defined. During Phase 2, the siting regions are explored from the surface and potential sites for subsurface exploration during Phase 3 are determined. During Phase 3, subsurface exploration is ex- 
ecuted and at least two potential sites will be finally assessed and compared. The site selection process ends with the final site decision. Each phase will be completed by a formal decision by the German Federal Parliament.

The siting process starts with a so-called blank map. During the siting process, the geological conditions will be assessed based on available data and the results from the surface and subsurface explorations, which will gradually reduce the number of potential siting regions and finally sites. This process is guided by predefined exclusion criteria, minimum requirements, geologic weighting criteria and preliminary safety assessments (Site Selection Act, 2017). The final decision on the site is projected in 2031.

The Federal Office for the Safety of Nuclear Waste Management (BASE) is the federal regulatory authority for radioactive waste disposal. BASE supervises the site selection process for the repository for high-level radioactive waste and is responsible for the accompanying public participation. To fulfil its tasks according to state-of-the-art science and technology, task related research is an integral part of BASE's activities. Current research activities in the context of the site selection process address geo-scientific questions, methodological aspects of the implementation of the site selection process, and public participation aspects. This contribution provides an overview on the current geo-scientific and methodological research activities at BASE.

\section{Research projects}

\subsection{Research on surface based exploration methods - the projects MessEr and überStand}

During Phase 2 of the German siting process (Fig. 1), the potential siting regions identified in Phase 1 and legally defined at the end of Phase 1 by decision of the German Federal Parliament are explored from the surface. BASE as the Federal Office for the Safety of Nuclear Waste Management has to review and define the respective exploration programs submitted by the implementer BGE (Bundesgesellschaft für Endlagerung $\mathrm{mbH}$ ). The surface exploration shall close knowledge gaps and gather data necessary for the application of the exclusion criteria, minimum requirements and weighting criteria during Phase 2 of the siting process. It also provides data necessary for execution of the respective preliminary safety assessment. The two projects MessEr (ongoing work by Gesellschaft für Anlagen- und Reaktorsicherheit (GRS) $\mathrm{gGmbH}$ ) and überStand (ongoing work by Brenk Systemplanung $\mathrm{GmbH}$ ) therefore compile and characterize available exploration methods from the surface with regard to the requirements laid out by the Site Selection Act. The combined results of both projects provide an orientation framework that contains a comprehensive compilation of structural, petrophysical, lithological, geophysical, hydrogeological, and hydrogeochemical methods for the investigation of possible sit- ing regions. The limitations and uncertainties of the different methods are discussed and based on the requirements of the Site Selection Act also aspects like the selection of suitable measurement methods are addressed.

\subsection{Research on active faults and fault zones - the project KaStör}

The Site Selection Act defines active fault zones as one of the exclusion criteria ( $\$ 22$ (2) 2 Site Selection Act). To be classified as an active fault zone according to the Site Selection Act, (i) faults or fault zones should show significant displacement along the faults as well as extensive fracture or damage zones and (ii) the movement along the faults or fault zones should have happened within the past 34 million years. Classification therefore not only requires simple detection of a fault or fault zone but also assessment their spatial and especially temporal activity. The project KaStör (carried out by Beak Consultants GmbH and Plejades GmbH; Brosig et al., 2020) therefore gives an overview of (i) the current state of knowledge on faults and fault zones in Germany and (ii) the commonly used methods for detection, interpretation and dating of faults and fault zones. As a result a work-flow for application of the exclusion criterion within the siting process was suggested. The evaluation of the results shows, that - outside seismically active areas - information on active faults and fault zones is very irregularly distributed in Germany. This partly reflects different tectonic histories of the different areas or coverage of faults and fault zones by un-faulted sediments. Partly this reflects the uneven distribution and depth of geological exploration, which typically focussed on areas with raw material potential/production or relevance for planning of large infrastructure projects. The studied and compiled methods include those for detection and localization of tectonic and atectonic faults and fault zones and those for direct or indirect detection of activity. Recent activity may be detected by in situ investigations or is based on longer time series measurements by, e.g., GPS, geodetic or geomorphological methods. Based on the different methods and the requirements of the Site Selection Act, Brosig et al. (2020) suggest a work-flow for application of the exclusion criterion within the siting process (Fig. 2). The authors recommend a four step work-flow: (i) Based on available data, potentially active faults and fault zones are identified. These should (ii) then be studied in more detail based on available and suitable methods. Those faults and fault zones that appear to be active should (iii) then be investigated with regard to specific fault and fault zone properties like offset, age and geometry. Finally, (iv) the faults and fault zones are judged according to $§ 22$ (2) 2 Site Selection Act. 


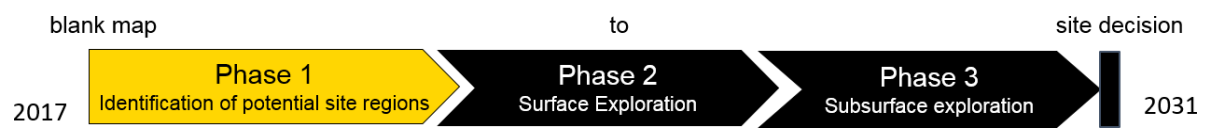

Figure 1. General succession of the phases within the stepwise German siting process. While Phase 1 only assess already available data, Phases 2 and 3 will base on results of surface and subsurface exploration programs.

\subsection{Research on temperature dependency of the different $\mathrm{THMC} / \mathrm{B}$ processes - the project Grenztemperatur}

The Site Selection Act defines $100^{\circ} \mathrm{C}$ as a draft limit on the temperature at the outer surface of the repository containers for the preliminary safety analyses ( 27 (4) Site Selection Act). This draft temperature limit should be valid due to precautionary reasons until pending research allows define host rock specific temperature limits. The project Grenztemperatur (carried out by Gesellschaft für Anlagen- und Reaktorsicherheit (GRS) gGmbH; Bracke et al., 2019) compiled the current state of knowledge on temperature dependent THMC/B processes as well as the international regulations and approaches towards repository temperature. The aim of the project was to identify the temperature dependency of the different THMC/B processes in the different potential host rocks (rock salt, clay stone, crystalline rock) and by this the host rocks specific temperature tolerance and to assess the influence of temperature on retrievability /recovery, as required by the Site Selection Act. Based on available FEP catalogues for rock salt (Wolf et al., 2012), clay stone (Jobmann et al., 2017), and crystalline rock (GRS gGmbH, unpublished) the relevant THMC/B processes were identified and their temperature dependency studied. No predefined temperature limits were found in other national regulations although guidelines may provide general requirements on design temperature. Disposal concepts with bentonite as buffer material typically show design temperatures $\leq 100^{\circ} \mathrm{C}$ within the buffer, except for the Swiss concept that allows higher temperature in the inner part of the bentonite buffer. The studied THMC/B processes clearly show that temperature may have positive or negative effects on the respective processes. Any safety related assessment of temperature limits or design temperatures therefore requires underlying safety and disposal concepts that define or allow to assess the role of the different $\mathrm{THMC} / \mathrm{B}$ processes from a safety point of view.

\subsection{Research on safety oriented weighting and comparison of siting criteria - the project MABeSt}

During the entire siting process, geo-scientific weighting criteria are repeatedly applied in Phases 1 to 3. General application of the geo-scientific weighting criteria is described in $\S 24$ of the Site Selection Act while the exact content of the different geo-scientific weighting criteria is defined in Appendices 1 to 11 to the Site Selection Act. Three groups of geo-scientific weighting criteria are defined: group 1 ad- dresses the achievable quality of containment and the robustness of evidence, group 2 addresses the preservation of the isolation potential, and group 3 covers further safety relevant properties of the disposal system. For each weighting criterion, assessment relevant properties with specific evaluation parameters or indicators are defined within Appendices 1 to 11 to $\S 24$ Site Selection Act. For each evaluation parameter or indicator, quantitative or qualitative values are defined to allow assigning the respective properties into individual assessment groups ranging from, e.g., favourable to less or unfavourable. Overall assessment of the geological situation of individual siting regions or sites based on the geo-scientific weighting criteria therefore requires aggregation of the assessments of the individual parameters and indicators. In addition to aggregation and assessment of individual siting regions and sites, a safety oriented comparative assessment of the different siting regions and finally (of at least two) sites is required. The project MABeSt (carried out by Gesellschaft für Anlagen- und Reaktorsicherheit (GRS) gGmbH; Frieling et al., 2020) compiles and assesses available methodological approaches to such a multi-criteria problem. According to the authors, well-suited are multi-criteria methods that belong to multi attribute decision making (MADM). Of these, especially outranking methods appear to be advantageous as they inherently allow comparative assessment of different criteria. According to the project results (Frieling et al., 2020), the multi-criteria problem could be split into different, hierarchical target levels (Fig. 3) and finally indicators.

Based on such a hierarchical target system, the different indicators/criteria can be aggregated. Such a hierarchical target system also allows the assessment (and eventually optimization) of different options at the individual target levels. However, despite the different multi-criteria methods applied, the authors clearly state that a verbal-argumentative assessment is necessary for, e.g., the chosen weighting of the different criteria/attributes and assessment of the robustness. Therefore, the chosen method for aggregation can only be a tool to support and substantiate the decision.

\subsection{Research on potential percolation mechanisms within rock salt - the project PeTroS}

Rock salt (i.e. halite, $\mathrm{NaCl}$ ) is one of the potential host rocks addressed in the Site Selection Act and is typically considered tight with regard to gas and saturated brine unless either the minimum stress criterion or the dilatancy criterion (both typically called "percolation thresholds") is infringed. However, Lewis and Holness (1996) measured dihedral angles $\Theta$ 


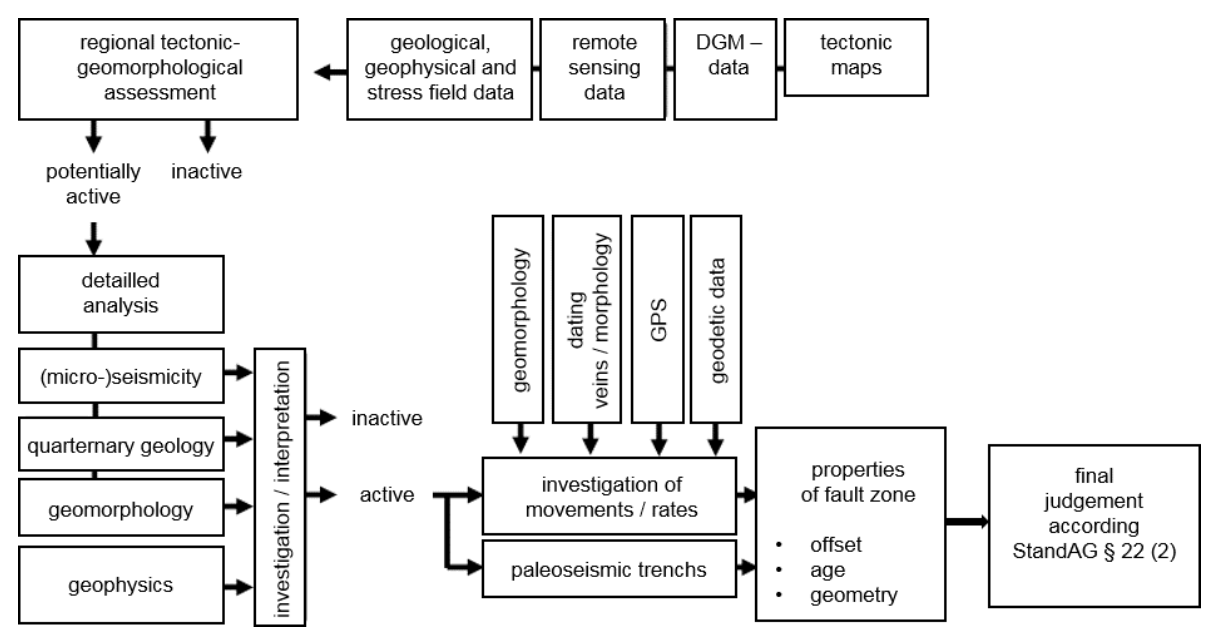

Figure 2. Suggested principal work-flow for the identification and characterization of active faults and fault zones and application of the exclusion criterion of $\S 22$ (2) 2 Site Selection Act according to Brosig et al. (2020). Modified after Decker et al. (2017).

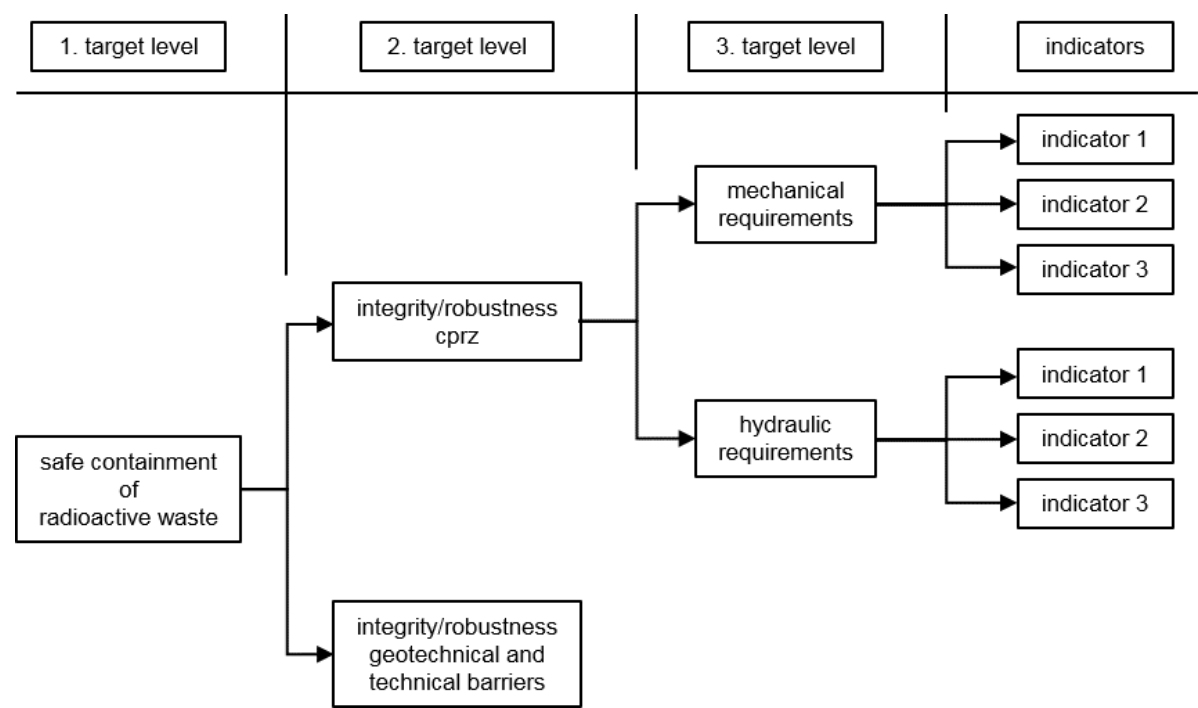

Figure 3. Splitting of a multi-criteria problem into different, hierarchical target levels and finally indicators. Aggregation of data and results is done on the different target levels. After Frieling et al. (2020).

(i.e. contact angle between salt grains and pore fluid) in the two-phase system brine-halite (pure halite, water in excess), noticing that $\Theta$ generally decreases with increasing $p$ and $T$. Based on the "static pore-scale theory", they postulated isolated fluid-filled pores and lack of permeability for $\Theta$ clearly above $60^{\circ}$ and an interconnected pore-fluid network along grain boundaries with correspondingly higher permeability for $\Theta$ clearly below $60^{\circ}$. For $\Theta \sim 60^{\circ}$, they assumed a transition zone. Based on the results by Lewis and Holness (1996) and experiments with compacted sodium chloride grains, Ghanbarzadeh et al. (2015) speculated that rock salt may lose its tightness and become permeable at $p-T$ conditions relevant for deep geologic nuclear waste disposal. Ghanbarzadeh and co-workers also postulated a deformation-assisted per- colation as a further mechanism that may increase permeability of rock salt even at low $p-T$ conditions for which $\Theta>60^{\circ}$. They speculated that at low deviatoric stresses, fluid-triggered recrystallization together with pressure dissolution could result in potential leakiness of a rock salt barrier, even below the classical percolation thresholds. To evaluate their hypotheses of potentially high permeability of rock salt at $p-T$ conditions relevant to deep geologic nuclear waste disposal, the project PeTroS (carried out by Institute of Geomechanics GmbH Leipzig IfG; Minkley et al., 2020) performed triaxial flow-through experiments on natural rock salt samples from German salt deposits. The experiments were performed at $18 \mathrm{MPa}$ with 160 and $180^{\circ} \mathrm{C}$ and at $36 \mathrm{MPa}$ with 140,160 and $180^{\circ} \mathrm{C}$. The run conditions of $36 \mathrm{MPa}$ and 


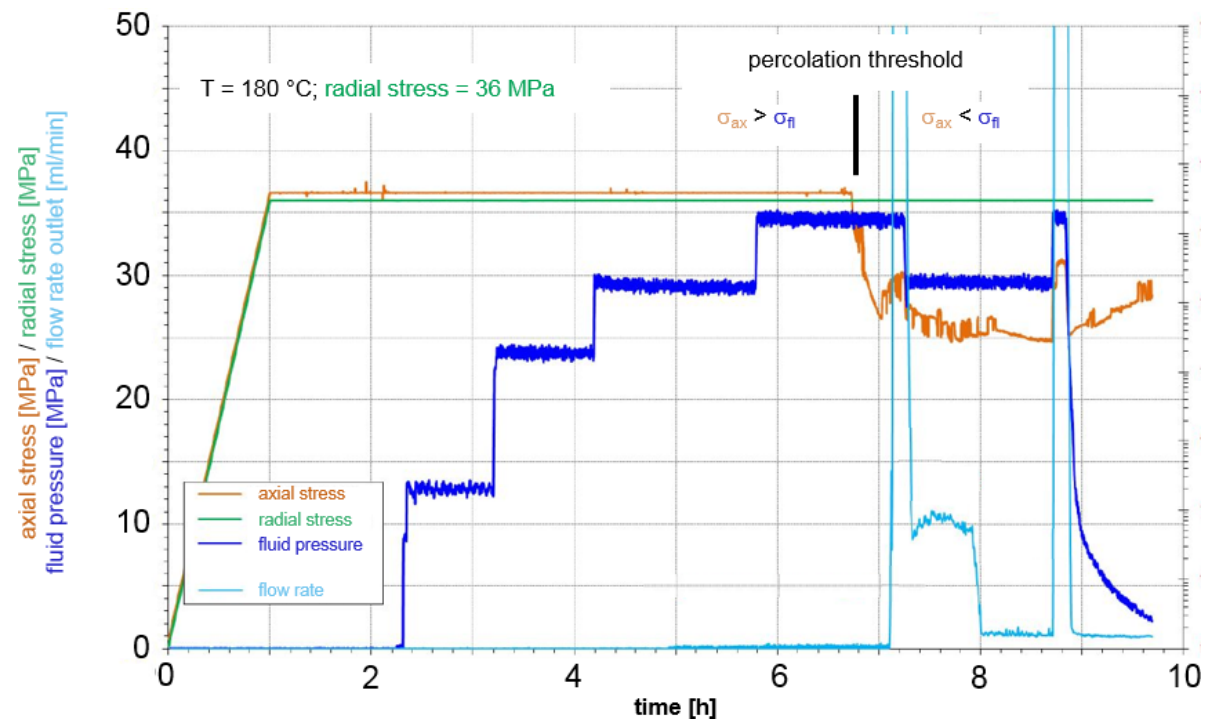

Figure 4. Example of a typical experimental run. After heating to the desired run temperature, axial and radial pressures are increased to isotropic experimental pressure conditions. Then the injection fluid pressure is increased stepwise up to near confinement pressure. The minimum stress criterion $\left(\sigma_{\mathrm{fl}}>\sigma_{\mathrm{min}}\right)$ is infringed by lowering the axial pressure below the fluid pressure. After passing this percolation threshold, discrete and significant fluid breakthrough is observed. Modified after Minkley et al. (2020).

$180^{\circ} \mathrm{C}$ correspond to $\Theta<60^{\circ}$ according to the data by Lewis and Holness (1996), all other run conditions correspond to the transition zone with $\Theta \sim 60^{\circ}$. At each $p-T$ combination, two experiments with either nitrogen gas or saturated $\mathrm{NaCl}-$ brine as injected fluid were executed. The cylindrical rock salt samples (length $200 \mathrm{~mm}$, diameter $100 \mathrm{~mm}$ ) were drilled out of larger natural core samples. The integrity of the prepared samples was controlled by ultrasonic measurements. A typical run layout consist of three phases (Fig. 4): First, the samples were heated and isotropic pressure conditions were established (Phase 1). Then, the fluid injection started and the fluid injection pressure was raised stepwise to slightly below confinement pressure (Phase 2). Finally, the axial stress was reduced until the minimum stress criterion was infringed and the fluid breakthrough due to pressure-driven percolation was detected (Phase 3). Fluid flow was monitored continuously at the outlet side of the system.

All experiments show none or probably insignificantly low fluid flow during Phase 2 at pressure conditions below the percolation threshold. The minor fluid flows in some of the experiments probably reflect undetected damages due to sample preparation or a scale effect due to small sample size compared to grain size (Minkley et al., 2020); however, an extremely low permeability as reason for the detected marginal fluid flows cannot be excluded unequivocally. During Phase 3, i.e. after infringement of the minimum stress criterion, all samples show distinct breakthrough of the injected fluid and clearly prove the existence of a percolation threshold, at least under the studied experimental conditions. Overall, the potentially high permeability of rock salt under the studied $p-T$ conditions, postulated by the "static pore-scale theory" (Lewis and Holness, 1996; Ghanbarzadeh et al., 2015), could not be validated by the performed experiments (for a critical discussion of the effects of brine composition on the dihedral angle and transferability of the Lewis and Holness (1996) data to natural systems, see: Rimsza and Kuhlman, 2020). Deformation-assisted percolation as the second possible process for increased permeability postulated by Ghanbarzadeh et al. (2015) was not experimentally studied within PeTroS as experiments were performed under quasi-isotropic pressure conditions without any deviatoric stress. However, the experimental results provide evidence that the minimum stress criterion is the major percolation threshold in rock salt, at least under the studied conditions, a mechanism that has not been discussed in the work by Ghanbarzadeh et al. (2015). The postulation by Ghanbarzadeh et al. (2015) of deformation-assisted percolation within rock salt as major percolation process is therefore questionable, although future studies may be required to ascertain the state of knowledge regarding fluid percolation in rock salt or tightness of rock salt under deforming conditions.

\section{Conclusion}

The presented research projects form part of the broad research portfolio of BASE. The research topics of BASE are solely derived from its statutory tasks and the results primarily serve to support BASE in fulfilling its tasks as national regulator within the German site selection process according to state-of-the-art science and technology. However, the re- 
sults of the projects may also be relevant to other stakeholders of the siting process.

The projects MessEr, überStand and Grenztemperatur predominantly compiled and reviewed current state-of-the-art science and technology in their respective fields. The compilation and characterization of available exploration methods from the surface by MessEr and überStand will also help inform the general public and allow it to understand and assess the surface exploration programme executed by BGE during Phase 2 of the siting process. Grenztemperatur did not provide new original data that would allow determine a host-rock specific temperature limit according to § 27 (4) of the Site Selection Act, but its results identify methodological approaches for the definition of such safety guided temperature limits and will support execution of the preliminary safety analyses during the siting process. The projects MABeSt and KaStör developed and provided methodological approaches for the general and specific application of the geoscientific criteria and requirements laid down in the Site Selection Act. By this, both projects will also support the definition of the exploration programmes during Phases 2 and 3 of the siting process. The project PeTroS addressed open questions regarding permeability of rock salt that were raised in the literature and performed the first triaxial flowthrough experiments on natural rock salt samples at the relevant $p-T$ conditions. The experiments could not validate the potentially high permeability of rock salt under the studied $p-T$ conditions, postulated in the literature based on the "static pore-scale theory". The results indicate that the minimum stress criterion and/or the dilatancy criterion are the prime "percolation thresholds" in rock salt.

Data availability. Data to the presented research projects are available via the published reports within Ressortforschungsberichte zur Sicherheit der nuklearen Entsorgung. Reports to projects messEr and überStand are in press and not yet published but will appear within Ressortforschungsberichte zur nuklearen Entsorgung and can be searched via DORIS - Digitales Online Repositorium und Informations-System, https://doris.bfs.de (last access: 3 December 2020).

Author contributions. AL prepared the manuscript with contributions from all co-authors and handled the review process. $\mathrm{CB}$ initiated and supervised the projects PeTroS and überStand and provided support during writing of the article and the review process. MJ initiated and supervised the project MessEr and provided support during writing of the article and the review process. UMR initiated and supervised the projects Grenztemperatur, MABeSt and KaStör and provided support during writing of the articel and the review process. CR co-supervised the project PeTroS and provided support during writing of the article and the review process.
Competing interests. The authors declare that they have no conflict of interest.

Special issue statement. This article is part of the special issue "European Geosciences Union General Assembly 2020, EGU Division Energy, Resources \& Environment (ERE)". It is a result of the EGU General Assembly 2020, 4-8 May 2020.

Acknowledgements. Editorial handling by Michael Kühn and constructive reviews by Kristopher Kuhlman and an anonymous reviewer are gratefully acknowledged.

Review statement. This paper was edited by Michael Kühn and reviewed by Kristopher Kuhlman and one anonymous referee.

\section{References}

Bracke, G., Hartwig-Thurat, E., Larue, J., Meleshyn, A., and Weyand, T.: Untersuchungen zu den "maximalen physikalisch möglichen Temperaturen" gemäß § 27 StandAG im Hinblick auf die Grenztemperatur an der Außenfläche von Abfallbehältern, Ressortforschungsberichte zur Sicherheit der nuklearen Entsorgung, BfE-RESFOR-003/19, Salzgitter 2019, available at: http://nbn-resolving.de/urn:nbn:de:0221-2019111520402 (last access: 3 December 2020), 2019.

Brosig, A., Bräutigam, B., Barth, A., and Stanek, K. P.: Evaluierung des Kenntnisstandes von aktiven Störungszonen in Deutschland (KaStör) - Vorhaben 4717F01301, Ressortforschungsberichte zur Sicherheit der nuklearen Entsorgung, BfE-RESFOR-004/20, Berlin 2020, available at: http://nbn-resolving.de/urn:nbn:de: 0221-2020062322220, last access: 3 December 2020.

Decker, K., Hirata, K., and Groudev, P.: Guidance document on practices to model and implement EARTHQUAKE hazards in extended PSA (final version) Volume 1, Technical report Advanced Safety Assessment Methodologies: extended PSA, IRSN, France, IRSN-PSN-RES-SAG-2017-00004-V1, 2017.

Frieling, G., Fischer-Appelt, K., Beuth, T., and Bracke, G.: Methoden für sicherheitsgerichtete Abwägungen und vergleichende Bewertungen im Standortauswahlverfahren (MABeSt) - Vorhaben 4718F13001, Ressortforschungsberichte zur Sicherheit der nuklearen Entsorgung, BfE-RESFOR-005/20, Berlin 2020, available at: http://nbn-resolving.de/urn:nbn:de: 0221-2020062422234, last access: 3 December 2020.

Ghanbarzadeh, S., Hesse, M. A., Prodanovic, M., and Gardner, J. E.: Deformation-assisted fluid percolation in rock salt, Science, 350, 1069-1072, https://doi.org/10.1126/science.aac8747, 2015.

Jobmann, M., Bebiolka, A., Jahn, S., Lommerzheim, A., Maßmann, J., Meleshyn, A., Mrugalla, S., Reinhold, K., Rübel, A., Stark, L., and Ziefle, G.: Projekt ANSICHT, Sicherheits- und Nachweismethodik für ein Endlager im Tongestein in Deutschland, Synthesebericht, Gesellschaft für Anlagen- und Reaktorsicherheit (GRS) gGmbH, Bundesanstalt für Geowissenschaften und Rohstoffe (BGR), DBE TECHNOLOGY GmbH (DBETEC), TEC-19-2016-AB, 137 pp., 2017. 
Lewis, S. and Holness, M.: Equilibrium halite- $\mathrm{H}_{2} \mathrm{O}$ dihedral angles: High rock-salt permeability in the shallow crust?, Geology, 5, 431-434, https://doi.org/10.1130/00917613(1996)024<0431:EHHODA>2.3.CO;2, 1996.

Minkley, W., Lüdeling, Ch., and Naumann, D.: Überprüfung des perkolationsgetriebenen Transports von Fluiden im Wirtsgestein Steinsalz unter relevanten Bedingungen für ein Endlager (PeTroS) - Vorhaben 4717E03250, Ressortforschungsberichte zur Sicherheit der nuklearen Entsorgung, BfE-RESFOR-006/20, Berlin 2020, available at: http://nbn-resolving.de/urn:nbn:de: 0221-2020112023854, 2020.

Rimsza, J. M. and Kuhlman, K. L.: Surface energies and structure of salt-brine interfaces, Langmuir, 36, 2482-2391, 2020.
Site Selection Act: Gesetz zur Suche und Auswahl eines Standortes für ein Endlager für hochradioaktive Abfälle (Standortauswahlgesetz - StandAG), 5 May 2017 (BGBl. I S. 1074), last amended by Article 3 of the Act from 12 December 2019 (BGB1. I S. 2510), 2017.

Wolf, J., Behlau, J., Beuth, T., Bracke, G., Bube, C., Buhmann, D., Dresbach, C., Hammer, J., Keller, S., Kienzler, B., Klinge, H., Krone, J., Lommerzheim, A., Metz, V., Mönig, J., Mrugalla, S., Popp, T., Rübel, A., and Weber, J. R.: FEP-Katalog für die VSG, Dokumentation, Bericht zum Arbeitspaket 7 - Vorläufige Sicherheitsanalyse für den Standort Gorleben, GRS-283, GRS, Köln, 864 pp., 2012. 